\title{
Optimal Allocation of Capacitor Bank for Loss Minimization and Voltage Improvement Using Analytical Method
}

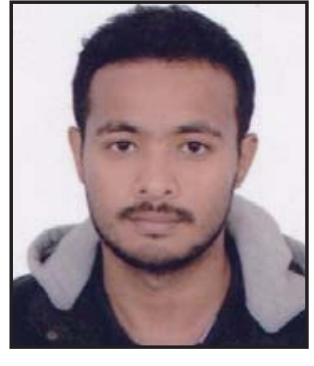

Avinash

Khatri KC

has received

his Master

Degree in

Planning and Operation of

Energy System from Kathmandu

University. He is currently working at Nepal Engineering

College as Jr. Prof. in

Department of Electrical and

Electronics Engineering. His

research interests are hybrid

energy, power system and artificial intelligence.

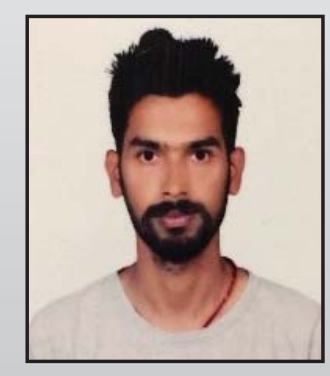

Tikaram

Regmi has

received

his Master

Degree in

Electrical Power Engineering from Kathmandu University. He is currently working at Nepal Engineering College as Jr. Prof. in Department of Electrical and Electronics Engineering. His research interests are renewable energy, power system and control system.

\author{
Avinash Khatri KC, Tika Ram Regmi ${ }^{+}$ \\ ${ }^{*}$ Nepal Engineering College, Department of Electrical and \\ Electronics Engineering, avinashkhatrikc@gmail.com \\ ${ }^{+}$Nepal Engineering College, Department of Electrical and \\ Electronics Engineering, tikabikramregmi@gmail.com
}

\begin{abstract}
An electric distribution system plays an important role in achieving satisfactory power supply. The quality of power is measured by voltage stability and profile of voltage. The voltage profile is affected by the losses in distribution system. As the load is mostly inductive on the distribution system and requires large reactive power, most of the power quality problems can be resolved with requisite control of reactive power. Capacitors are often installed in distribution system for reactive power compensation. This paper presents two stage procedures to identify the location and size of capacitor bank. In the first stage, the load flow is carried out to find the losses of the system using sweep algorithm. In the next stage, different size of capacitors are initialized and placed in each possible candidate bus and again load flow for the system is carried out. The objective function of the cost incorporating capacitor cost and loss cost is formulated constrained with voltage limits. The capacitor with the minimum cost is selected as the optimized solution. The proposed procedure is applied to different standard test systems as 12-bus radial distribution systems. In addition, the proposed procedure is applied on a real distribution system, a section of Sallaghari Feeder of Thimi substation. The voltage drops and power loss before and after installing the capacitor were compared for the system under test in this work. The result showed better voltage profiles and power losses of the distribution system can be improved by using the proposed method and it can be a benefit to the distribution networks.
\end{abstract}

Keywords : quality; voltage stability; voltage profile; capacitor cost; voltage limits.

\section{INTRODUCTION}

In context of Nepalese distribution system, the distribution lines are extended over long distances to feed loads scattered over large areas. Thus, the primary and secondary distributions lines in rural areas are largely radial laid usually extend over 
long distances. This results in high line resistance and therefore high $\mathrm{I}^{2} \mathrm{R}$ losses in the line. Not only significant loss due to the lengthy feeder, there will be the abrupt decrease in the voltage in the load end as the distance between source and load increases. Therefore load situated at the remote places suffers low voltage problems which arises different issues regarding power quality [1].

A major problem in a power distribution system is a voltage drop due to high-load, very long power distribution systems, and rapid load growth in a radial network. Voltage regulation is the primary constraint in the planning and sizing of rural distribution networks. The allowable voltage regulation limits and the assumptions adopted by distribution network planners and designers significantly affect the capital and lifetime costs of system. The problem of the losses and voltage drop in distribution feeders are dependent on each other and varies with the pattern of loading on the feeder. The distribution losses can be reduced by proper selection of distribution transformers, feeders, proper re-organization of distribution network, placing the shunt capacitor in appropriate places, and penetration of distributed generations at different point of distribution networks [2].

Capacitors are widely used in distribution systems for voltage stabilization and reactive power compensation as well as power/energy reduction, voltage regulation and system capacity release. The extent to which loss is minimized and voltage improves depends upon the proper selection of the size of capacitor bank and the position at which it is located [3].So, in order to maximize the benefits oriented from capacitor bank placement, the proper selection of the position and size is desirable.

\section{LITERATURE REVIEW}

A backward/forward sweep method is used to carry out the load flow of the radial distribution system. This sweep algorithm consists of two sets recursive equations. The first set of equations is used for the determination of the branch currents starting from the last branch and then proceeding to the root node in backward direction. The other equations to calculate the voltage magnitude and angle of each bus starting from central bus and moving towards the last bus in forward direction.
In backward sweep the branch current or the power flow is calculated starting from the branches in the last layer and moving towards the branches connected to the root node. The updated effective power flows in each branch are obtained in the backward propagation computation by considering the node voltages of previous iteration. It means the voltage values obtained in the forward path are held constant during the backward propagation and updated power flows in each branch are transmitted backward along the feeder using backward path. This indicates that the backward propagation starts at the extreme end node and proceeds towards source node [4]. The forward sweep is basically for the voltage drop calculation. Bus voltages are updated in a forward sweep starting from branches from starting bus towards last bus. The central bus or source bus is set at its rated value. During the forward propagation the effective power in each branch is held constant to the value obtained in backward flow [5].

A number of optimization methods have been developed for solving different types of optimization problems. A two stage process to determine the optimum size and location of capacitor banks to achieve maximum energy savings [6]. Loss sensitivity factor (LSF) is calculated in the first stage to find the optimum location and in second stage of the method an analytical procedure is presented to determine the size of the capacitor. While considering the maximum energy savings, the installation and operation costs of the capacitor banks are also investigated. In order to reduce the loss of distribution radial feeder a capacitor bank allocation is done [7]. A load flow process is carried out before and after the placement of capacitor banks. The buses with the voltage level below the $0.95 \mathrm{pu}$ are classified as weak buses. The different available size of capacitors is place at each weak buses and load flow is carried out. Then different cases are analyzed. Based on the lowest power loss, the optimal size and location for the capacitor bank is suggested. An analytical based solution model is proposed for capacitor placement to ensure power quality [6]. This method assumed that there are several identical capacitors are available at each and every bus and they can be placed one unit per bus at a time. 
At every iteration run, a capacitor is added to the possible candidate bus and each time the value of objective function is evaluated. Operational and equipment constraints are also checked. The unit that reduces the overall objective function the most, without causing any limit violations, is chosen and placed permanently at the respective bus.

In recent years, the optimization process has been modified from traditional mathematical programming techniques called as modern or non-traditional optimization methods. Among them, artificial intelligent (AI) is widely used. AI such as artificial neural network (ANN), genetic algorithm (GA), simulated annealing algorithm (SA), ant colony Optimization (ACO) and particle swarm optimization (PSO) are widely used optimization methods in recent years. A novel emerging intelligence based on particle swamp optimization (PSO) for optimum selection of distribution capacitors is presented in [8]. The solution search algorithm provided a global optimal solution for the capacitor bank selections. To overcome the limitations of PSO, hybrid algorithms with genetic algorithm (GA) [8]. The basis behind such a hybrid approach was to have merits of PSO with those of GA. The purpose of applying mutation to PSO is to increase the diversity of the population and the ability to have the PSO to avoid the local maxima.

\section{METHODOLOGY}

\section{A. Load Flow Analysis}

Load flow process is vital to the power system. It gives the steady state solution of the network as well as helps in the continuous monitoring of the running state of system. Generally, the $\mathrm{R} / \mathrm{X}$ ratio of the distribution system is very high resulting in the high voltage drop and power loss in the system. Due to this the conventional load flow algorithm such as Newton-Raphson and Fast Decoupled load flow methods may provide inaccurate results and also may fail to converge. In this work, in order to overcome convergence problem, a backward/forward sweep algorithm in [9] is used to carry out load flow of the distribution system.
B. Optimum Allocation of Capacitor by Analytical Method

The methodology based on analytical method discussed in the Fig. 1 determines the value of capacitor based on the cost associated with the active power losses and installation cost of capacitor bank in the distribution network. The process starts with normal load flow process. After carrying out load flow process the capacitor size $\left(\mathbf{Q}_{\mathrm{VAR}}\right)$ is randomly initialized between minimum and maximum value i.e. the minimum value is defined as zero and maximum value of capacitor is defined to be two times of the total reactive load of the system $\mathbf{Q}_{\text {load }}$.

$$
0<Q_{\text {VAR }}<2 Q_{\text {load }}
$$

The voltage of the bus is kept as constraint to be satisfied. Constraint defined for voltage regulation limit is considered from rule 40 [10] of Electricity Rules, 2050 (1993) and IEEE standard [11] i.e.

$$
0.95<\mathrm{V}_{\text {bus }}<1.05
$$

The objective function of this research work is to minimize the total cost base on the power losses and capacitor installation cost. The cost is divided into two parts.

i) Power loss Cost \&

ii) Capacitor Cost

\section{a. Cost of Losses}

The power loss of the branch is calculated by line current I and branch resistance $\mathrm{R}$ as $\boldsymbol{P}=\boldsymbol{I}^{2} \boldsymbol{R}$. The total power loss is evaluated by adding all the line

$$
\text { Total power loss }=\sum_{i=1}^{b} P_{i}
$$

losses, i.e.

Where, $b$ number of branches.

To evaluate the cost of the losses, the following data is considered. The power loss given by the load flow process is peak power loss. The average power loss is calculate by using loss of load factor (LLF), [13]

\section{LLF = Average Loss / Peak Loss,}


Therefore, the average loss is calculated as the peak power loss multiplied by LLF. The average power loss when multiplied by factor of 8760 gives the annual energy loss. The total cost of energy lost is calculated as given by the following equation.

\section{Annual Total Loss Cost $=\mathbf{L L F} *$ Total Active Power Loss * Unit Energy Cost * 8760}

\section{b. Capacitor Cost}

The cost of capacitor depends on the size of capacitor bank to be installed. Though cost of per unit size of capacitor varies from size to size i.e. per unit cost of capacitor of lower sized capacitor banks are more compared to per unit cost of large capacitor banks [6]. The cost for installation of capacitor bank in the distribution network is given as,

\section{Capacitor Cost $=\mathbf{k}_{\mathbf{c}} * \mathbf{Q}_{\mathrm{VAR}}$}

Where, $\mathbf{k}_{\mathbf{c}}$ is the unit cost of capacitor $\$ / \mathrm{kVAR}$, $\mathbf{Q}_{\mathrm{VAR}}$ is size of capacitor to be installed in kVAR.

The life of capacitor bank installed is assumed to be for 10 years. So, the cost of capacitor installed per annum is given by annuity factor A, which is calculated as,

$$
A=\frac{r}{1-(1+r)^{-n}}
$$

Where, $\mathbf{r}$ is the rate of return on investment and $\mathbf{n}$ is number of years. Assuming the $\mathrm{r}=10 \%$ and life of capacitor bank to be 10 years [13], thus annual Capacitor cost is given as,

\section{Annual Capacitor Cost $=$ A* Capacitor Cost}

\section{c. Objective function}

The objective function is defined as,

\section{Minimize, $\mathrm{F}=$ Annual Total Loss Cost + Annual Capacitor Cost}

The value of objective function is calculated for each size of solution without violating the constraint limits. The solution with the minimum value of total value of objective function will be the optimized solution. The optimized solution gives the minimum system loss under voltage constraints with the size and bus number where the capacitor bank is to be placed.

\section{Flowchart for optimum selection.}

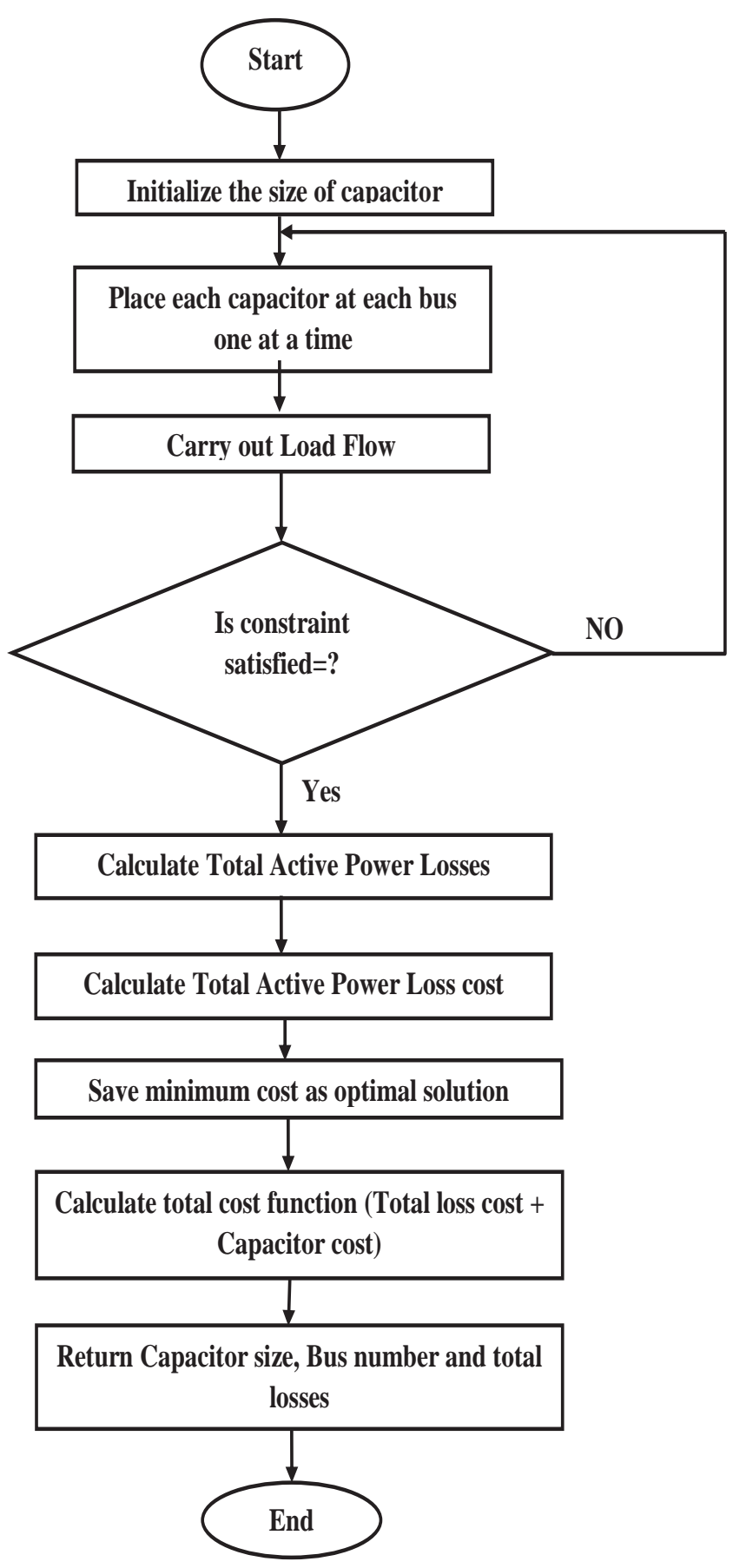

Fig.1 Flowchart for optimum size and location of capacitor 


\section{RESULTS}

The proposed method for optimal capacitor allocation for loss reduction was tested in the IEEE standard 12 bus radial distribution feeders and implemented on real radial distribution feeder of Nepalese system to calculate the total annual cost savings.

\section{a. IEEE-12 bus radial distribution system}

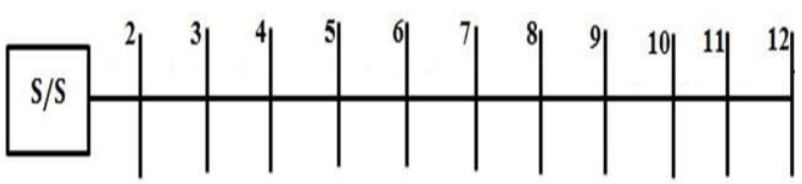

Fig. 2 Single line diagram of IEEE-12 bus system

The proposed method for capacitor placement was implemented to a 12-bus radial distribution test system. The single-line diagram of the $11 \mathrm{kV}$, 12-bus system is illustrated in Figure 2. Using this method, the capacitors of rating $233 \mathrm{kVAR}$ to be placed at the optimal location bus number 9 . The initial power loss was $20.3 \mathrm{~kW}$ and it reduced to $11.86 \mathrm{~kW}$ after capacitor placement using the proposed method. The results of the proposed method are shown in Table 1.

Table 1 Voltage of different buses of IEEE 12 Bus with and without Capacitor Bank

\begin{tabular}{|c|c|c|}
\hline \multirow{2}{*}{$\begin{array}{c}\text { Bus } \\
\text { Number }\end{array}$} & \multicolumn{2}{|c|}{ Voltage (pu) } \\
\cline { 2 - 3 } & $\begin{array}{c}\text { Without } \\
\text { Capacitor Bank }\end{array}$ & $\begin{array}{c}\text { With Capacitor } \\
\text { Bank }\end{array}$ \\
\hline 1 & 1 & 1.0000 \\
\hline 2 & 0.9944 & 0.9953 \\
\hline 3 & 0.9891 & 0.9911 \\
\hline 4 & 0.9808 & 0.9846 \\
\hline 5 & 0.9702 & 0.9767 \\
\hline 6 & 0.9670 & 0.9745 \\
\hline 7 & 0.9643 & 0.9726 \\
\hline 8 & 0.9537 & 0.9653 \\
\hline 9 & 0.9505 & 0.9639 \\
\hline 10 & 0.9477 & 0.9611 \\
\hline 11 & 0.9469 & 0.9602 \\
\hline 12 & 0.9467 & 0.9600 \\
\hline
\end{tabular}

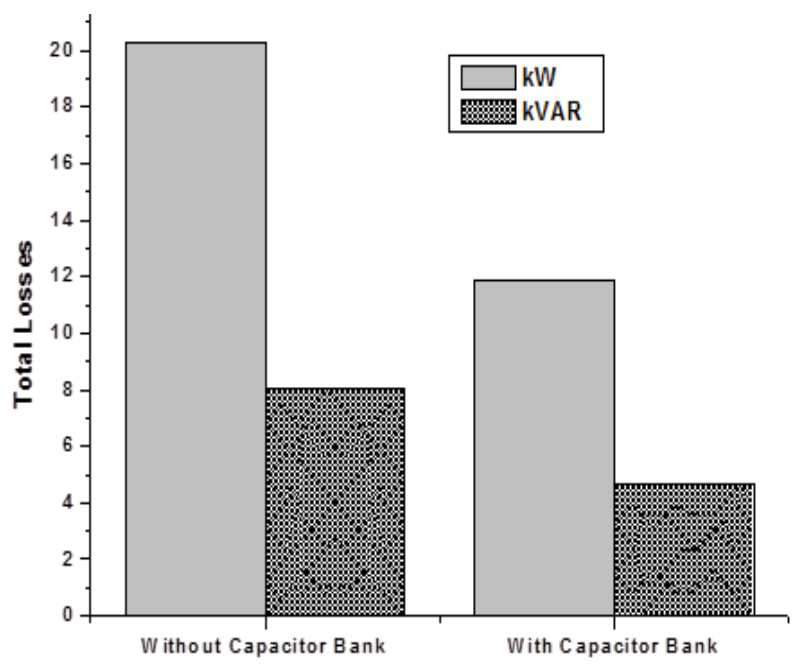

Fig.3 Total Losses of the system with and without Capacitor Bank

\section{b. Nepalese Radial Distribution System}

The figure 3 shows the single line diagram of section of Sallaghari feeder radial distribution feeder. The feeder consists of 11 buses. The system consists of two laterals from bus 2 . The description of the buses is provided in the table 4.6. The feeder is supplied from Thimi through $11 \mathrm{kV}$ lines at 100 MVA base. The feeder section consists of 3 transformers of Nepal Electricity Authority (NEA) and seven private transformers. The feeder supplies to the residential load as well as for the industries. The power factor of the transformer supplying to the residential area was considered to be 0.8 whereas it was kept 0.6 for industrial areas. The loads on the feeders were lumped at 11 different places. The total load in the system were $1103 \mathrm{~kW}$ and $1116 \mathrm{kVAR}$.

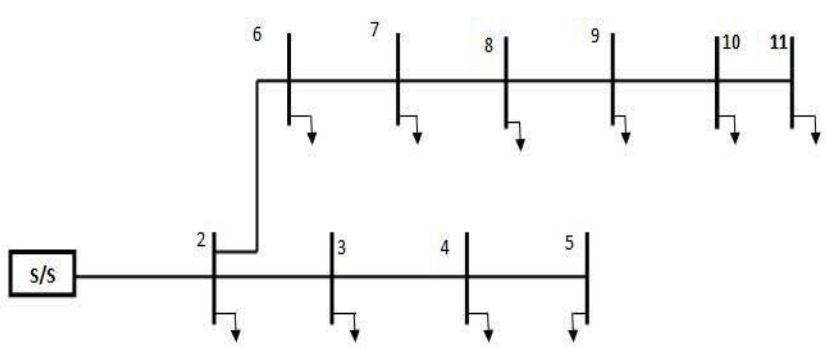

Fig. 4 Single line diagram for Sallaghari feeder

After running optimization program for the system, the required size of capacitor bank is found to be $907 \mathrm{kVAR}$ and the optimum location, bus 7 . The initial power loss was $55.23 \mathrm{~kW}$ and it was reduced to $31.32 \mathrm{~kW}$ after capacitor placement using the proposed method. The results of the proposed method are shown in Table 2. 
Table 2 Voltage of different buses of IEEE 12 Bus with and without Capacitor Bank

\begin{tabular}{|c|c|c|}
\hline \multirow{2}{*}{ Bus Number } & \multicolumn{2}{|c|}{ Voltage in pu } \\
\cline { 2 - 3 } & $\begin{array}{c}\text { Before } \\
\text { Capacitor }\end{array}$ & $\begin{array}{c}\text { After Capacitor } \\
\text { Placement }\end{array}$ \\
\hline 1 & 1.0000 & 1.0000 \\
\hline 2 & 0.9686 & 0.9818 \\
\hline 3 & 0.9627 & 0.9761 \\
\hline 4 & 0.9587 & 0.9720 \\
\hline 5 & 0.9563 & 0.9697 \\
\hline 6 & 0.9606 & 0.9795 \\
\hline 7 & 0.9524 & 0.9780 \\
\hline 8 & 0.9490 & 0.9747 \\
\hline 9 & 0.9463 & 0.9721 \\
\hline 10 & 0.9441 & 0.9700 \\
\hline 11 & 0.9433 & 0.9692 \\
\hline
\end{tabular}

The load flow analysis gave the voltage profile of the system under study and different losses occurring at different segments of the system. The voltage was minimum at bus 11 which was equal to 0.9433 pu and in a similar fashion the voltages at bus 8,9 and 10 were also below acceptable limits. The total loss of the system was equal to $55.23 \mathrm{~kW}$ and $51.68 \mathrm{kVAR}$.

The voltages at bus $8,9,10$ and 11 which were below 0.95 pu previously improved above $0.95 \mathrm{pu}$ after the introduction of capacitor bank at bus 7 . The comparison of voltages at different buses before and after capacitor bank is represented by Fig. 4 .

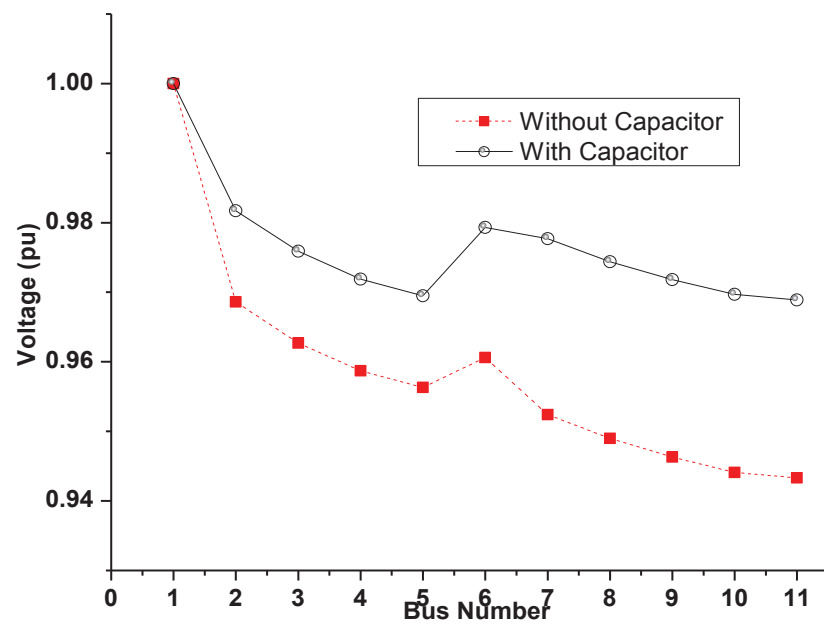

Fig.5 Voltage profile of feeder with and without Capacitor
Table 3 Summary of results before and after capacitor placement

\begin{tabular}{|c|c|c|c|}
\hline \multicolumn{2}{|c|}{} & $\begin{array}{c}\text { Base Case } \\
\text { (Without } \\
\text { Capacitor) }\end{array}$ & $\begin{array}{c}\text { With } \\
\text { Capacitor }\end{array}$ \\
\hline $\begin{array}{c}\text { Voltage } \\
(\mathrm{pu})\end{array}$ & Min & 0.9433 & 0.9686 \\
\cline { 2 - 4 } Total Loss & Active(kW) & 0.9689 & 0.9817 \\
\cline { 2 - 4 } & $\begin{array}{c}\text { Reactive } \\
(\mathrm{kVAR})\end{array}$ & 51.68 & 31.32 \\
\hline \multirow{2}{*}{\begin{tabular}{c} 
Capacitor \\
\cline { 2 - 4 }
\end{tabular}} & $\begin{array}{c}\text { Size (kVAR) } \\
\text { Location (Bus } \\
\text { Number) }\end{array}$ & - & 907 \\
\hline $\begin{array}{c}\text { Loss } \\
\text { Reduction }\end{array}$ & $\begin{array}{c}\text { Active Power } \\
(\mathrm{kW})\end{array}$ & - & 23.91 \\
\hline \multicolumn{2}{|c|}{ Total Loss Cost(\$) } & 24190.74 & 13718.16 \\
\hline Capacitor Cost(\$) & - & 72.56 \\
\hline \multicolumn{2}{|c|}{ Total Annual Cost(\$) } & - & 13790.72 \\
\hline \multicolumn{2}{|c|}{ Net Annual Savings (\$) } & 10400.02 \\
\hline
\end{tabular}

Table 3 summarizes the result for the load flow of section of Sallaghari feeder. The results show that the minimum voltage of the feeder was $0.9433 \mathrm{pu}$ at bus 11 and maximum value of voltage was $0.9689 \mathrm{pu}$ at bus 2. After the installation of the capacitor bank the minimum and maximum voltages were found to be 0.9686 and 0.9817 per unit at bus 11 and bus 2 respectively. Similarly, there is significant reduction in active as well as reactive power loss. The graph showing the comparison of loss with and without capacitor placement is shown in Fig.5 below. The installation of capacitor at the proposed location shows the annual profit of $\$ 10,400$.

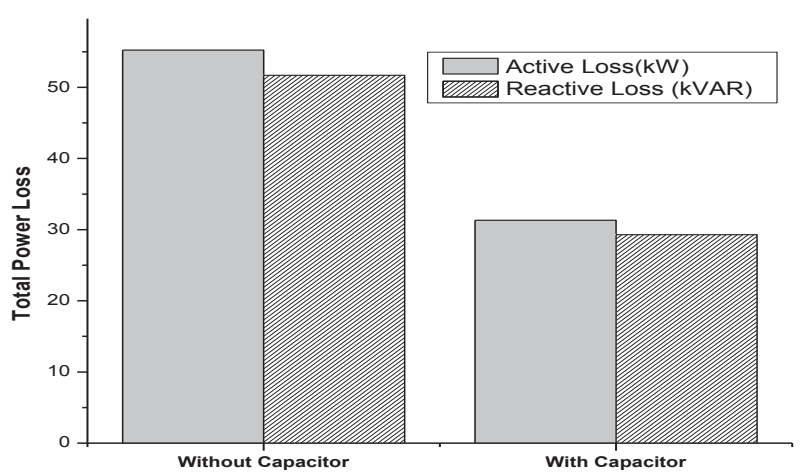

Fig.6 Total Losses with and without Capacitor Bank 


\section{CONCLUSIONS}

Capacitors are often installed in distribution system for reactive power compensation to carry out power and energy loss reduction. Size and location are crucial factors in the application of capacitor for loss minimization. The appropriate placement of capacitors is also important to ensure that system power losses and total investment capacitor costs are minimal. The voltage drops and power loss before and after installing the capacitor were compared in this work. The result showed better voltage profiles and power losses of the distribution system could be improved by using the proposed method and it can be a benefit to the distribution networks.

\section{RECOMMENDATION}

The approach described in this research work considers only the optimal size and location of capacitor bank; objective function can be formulated to determine the optimal number of locations for capacitor bank along with size and position. Future work will be dedicated to incorporate the different types of load models, load growth and multi-load level.

\section{References}

[1] K. V. S. R. Murthy and M. R. Raju, "Electrical Energy Loss in Rural Distribution Feeders- a Case Study," Power, vol. 12, no. 2, pp. 14-1, 2007.

[2] A. A. Abou El-Ela, M. T. Mouwafi, A.-M. Kinawy, and R. A. El-Sehiemy, "Optimal capacitor placement in distribution systems for power loss reduction and voltage profile improvement," IET Gener. Transm. Distrib., vol. 10, no. 5, pp. 12091221, 2016.

[3] A. . S. Allw, M. S. Almurieb, and Z. A. Alamidy, "Reduction Power losses on distribution feeders in Electrical Distribution Systems."

[4] S. Sunisith and K. Meena, "Backward / Forward Sweep Based Distribution Load Flow Method," vol. 5, no. 9, pp. 1539-1544, 2014.
[5] J. Rupa and S. Ganesh, "Power Flow Analysis for Radial Distribution System Using Backward/ Forward Sweep Method," World Acad. Sci. Eng., vol. 8, no. 10, pp. 1621-1625, 2014.

[5] P. V. Babu and S. P. Singh, "Capacitor allocation in radial distribution system for maximal energy savings," 2016 Natl. Power Syst. Conf., no. February 2017, pp. 1-6, 2016.

[6] K. Tilakul, P. Buasri, A. Kaewrawang, and J. Triyangkulsri, "Capacitor Location and Size Determination to Reduce Power Losses of a Distribution Feeder in Lao PDR," vol. 4, no. 1, pp. 32-36, 2012.

[7] B. Gou and A. Abur, "Optimal capacitor placement for improving power quality," Power Eng. Soc. Summer Meet. ..., pp. 488-492, 1999.

[8] A. M. Sharaf and A. A. A. El-Gammal, "Optimal selection of capacitors in distribution networks for voltage stabilization and loss reduction," EPEC 2010 - IEEE Electr. Power Energy Conf. "Sustainable Energy an Intell. Grid," 2010.

[9] A. Wazir and N. Arbab, "Analysis and Optimization of IEEE 33 Bus Radial Distributed System Using Optimization Algorithm," J. Emerg. Trands Appl. Eng., vol. 1, no. 2, 2016.

[10] Government of Nepal, "Electricity Rules," vol. 2050, no. 1993, pp. 1-68, 1993.

[11]"IEEE SA - 141-1993 - IEEE Recommended Practice for Electric Power Distribution for Industrial Plants." [Online]. Available: https:// standards.ieee.org/findstds/standard/141-1993. html. [Accessed: 25-Aug-2017].

[12] K. Malmedal and P. K. Sen, "A Better Understanding of Load and Loss Factors," in 2008 IEEE Industry Applications Society Annual Meeting, 2008, pp. 1-6.

[13] R. S. Rao and S. V. L. Narasimham, "Optimal capacitor placement in a radial distribution system using plant growth simulation algorithm," Int. J. Electr. Comput. Energ. Electron. Commun. Eng., vol. 2, no. 9, pp. 1971-1978, 2008. 